\section{International Scientific Journal} Theoretical \& Applied Science

p-ISSN: 2308-4944 (print) e-ISSN: 2409-0085 (online)

Year: 2017 Issue: $05 \quad$ Volume: 49

Published: 27.05.2017 http://T-Science.org
Meyrbek Inkarbekuly Azbergen

Cand.tech.Sciences, Professor,

Taraz state University.M.X.Dulati.

Nuradil Meyrbekuly Inkarbek engineer

National center for personnel management of civil service of Kazakhstan.

SECTION 8. Architecture and construction.

\title{
THE INFLUENCE OF PRELIMINARY CYCLIC LOADING ON DEFORMATION AND STRENGTH OF SANDY SOILS
}

Abstract: The article presents the results and experimental data on the study of deformation and strength of sandy soil considering influence of preliminary cyclic exposure.

Key words: soil, sand, loading, deformation, cyclic effect.

Language: Russian

Citation: Azbergen MI, Inkarbek NM (2017) THE INFLUENCE OF PRELIMINARY CYCLIC LOADING ON DEFORMATION AND STRENGTH OF SANDY SOILS. ISJ Theoretical \& Applied Science, 05 (49): 173176.

Soi: http://s-o-i.org/1.1/TAS-05-49-26 Doi: crossef https://dx.doi.org/10.15863/TAS.2017.05.49.26

УДК 624.13

\section{ВЛИЯНИЕ ПРЕДВАРИТЕЛЬНОГО ЦИКЛИЧЕСКОГО НАГРУЖЕНИЯ НА ДЕФОРМИРУЕМОСТЬ И ПРОЧНОСТЬ ПЕСЧАНЫХ ГРУНТОВ}

Аннотация: В статье представлены результаты и экспериментальные данные по исследованию деформируемости и прочности песчаных грунтов с учетом влияния предварительного ициклческого воздействия.

Ключевые слова: грунт, песок, нагруженцие, деформация, ичиклическое воздействие.

\section{Introduction}

Для зданий и сооружений, работающих в квазистатическом режиме и претерпевающих на определенном этапе действие циклических воздействий, важным является оценка влияния последних на деформируемость и прочность грунтов их оснований.

С этой целью выполнены четыре серии испытаний. Эксперименты проведены в приборах трехосного сжатия конструкции Э.И.ВоронцоваМ.И.Азберген [3,5-8]. Исследованы песчаные грунты двух типов: песок мелкий и песок средней крупности. Грунты однородны, средней плотности сложения.

\section{Materials and Methods}

Первая и вторая серии экспериментов посвящены изучению прочности и деформируемости грунтов при статическом (однократном) нагружении. В испытаниях использованы грунты обеих типов. На первом этапе грунты подвергались изотропному обжатию с заданным давлением, на втором этапе проводилось девиаторное нагружение с возрастающим средним нормальным напряжением до разрушения образца грунта.

В третьей и четвертой серии экспериментов изучались влияние предварительного циклического воздействия на прочность и деформируемость грунтов. Испытания проведены с песком мелким в воздушно-сухом состоянии и песком средней крупности при двух состояниях по влажности (воздушно-сухом и влажности 0,04). На первом этапе грунты подвергались изотропному обжатию с заданным давлением, на втором этапе при достижении девиаторного нагружения заданного уровня напряжений $\sigma_{i} / \sigma_{i}^{*}$ производилась частичная разгрузка на величину $n=\sigma^{u} / \sigma^{c m}$ и квазистатическое циклическое воздействие с заданной амплитудой $n$ до стабилизации приращений деформаций, после чего приложением статической нагрузки образец грунта доводился до разрушения по 


\begin{tabular}{|c|c|c|c|c|c|c|}
\hline Impact Factor: & $\begin{array}{l}\text { ISRA (India) } \\
\text { ISI (Dubai, UAF } \\
\text { GIF (Australia) } \\
\text { JIF }\end{array}$ & $\begin{array}{l}=1.344 \\
=0.829 \\
=0.564 \\
=1.500\end{array}$ & $\begin{array}{l}\text { SIS (USA) } \\
\text { PИHЦ (Russia) } \\
\text { ESJI (KZ) } \\
\text { SJIF (Morocco }\end{array}$ & $\begin{array}{l}=0.912 \\
=\mathbf{0 . 2 3 4} \\
=\mathbf{3 . 8 6 0} \\
=\mathbf{2 . 0 3 1}\end{array}$ & $\begin{array}{l}\text { ICV (Poland) } \\
\text { PIF (India) } \\
\text { IBI (India) }\end{array}$ & $\begin{array}{l}=6.630 \\
=1.940 \\
=4.260\end{array}$ \\
\hline
\end{tabular}

траектории «раздавливания» (рис.1, траектория

П).
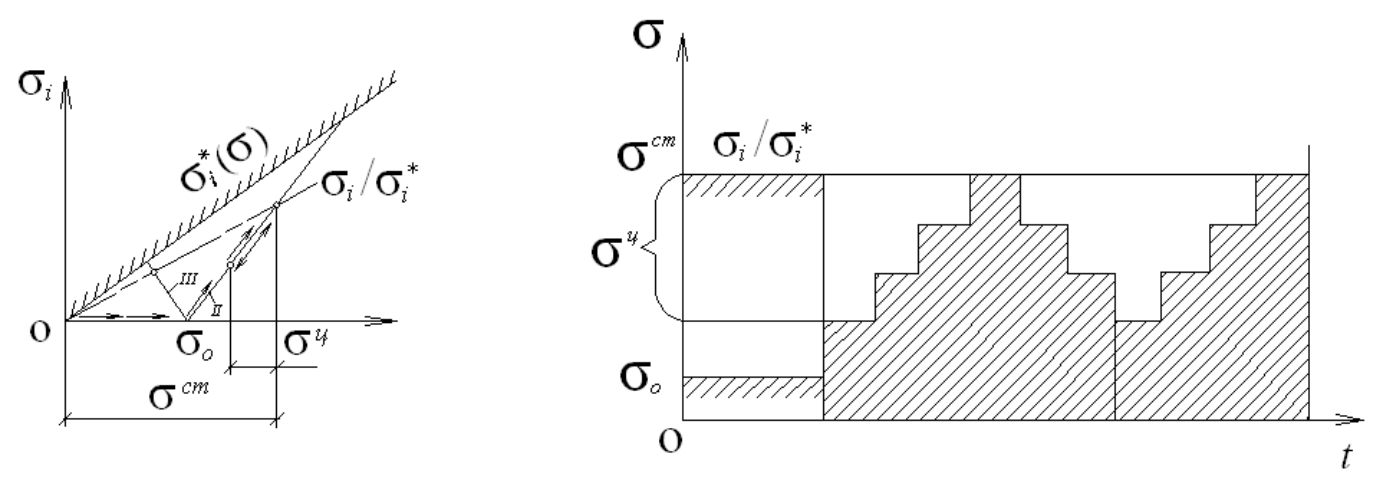

Рисунок 1 - Траектории и режимы циклической нагрузки.

С методикой проведения таких испытаний более подробно можно ознакомиться в работах [4-8].

Как показывают результаты испытания грунтов при статических (однократных) нагружениях по траектории П (рис.2-3, кривые 1), характер объемного и сдвигового деформирования песков мелкого и средней крупности в воздушно-сухом состоянии идентичен. Однако, песок средней крупности имеет гораздо большую, чем песок мелкий, склонность к уплотнению.

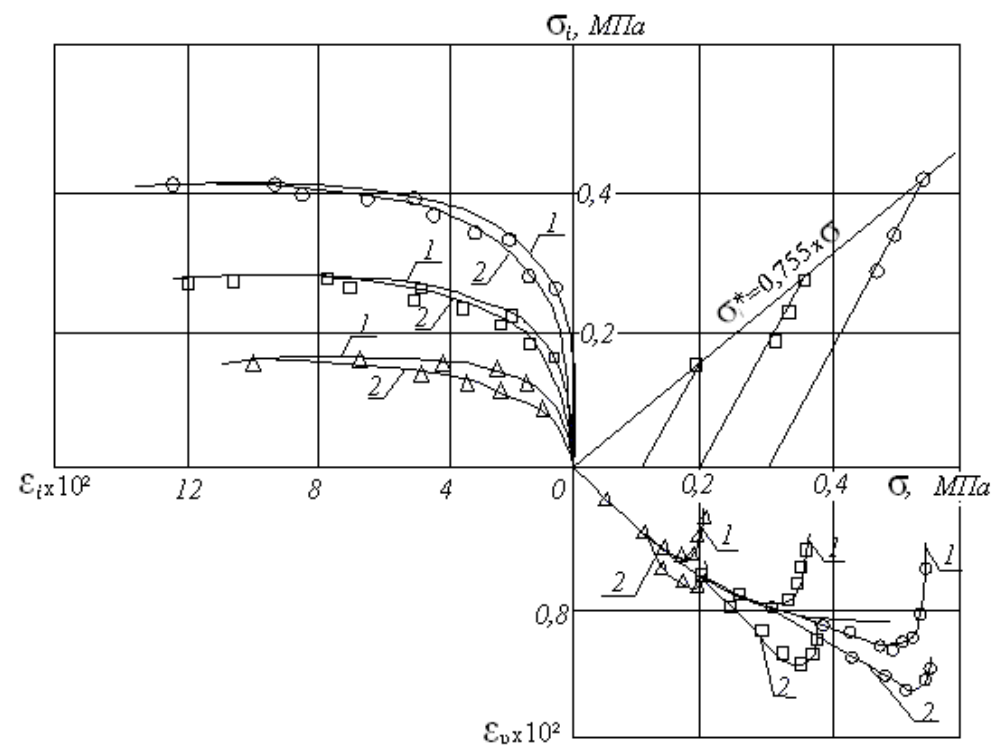

Рисунок 2 - Паспорт испытания грунта.

Мелкий песок, в воздушно-сухом состоянии: 1-статика; 2-циклика

Влияние предварительного циклического воздействия на деформируемость грунтов характеризуется развитием дополнительных как объемных, так и сдвиговых деформаций по сравнению с однократным нагружением (кривые 2 на рис.2-3). В области статистического девиаторного уплотнения объемная деформируемость характеризуется доуплотнением по сравнению с однократным нагружением [1,2]. Величина этого доуплотнения, при прочих равных условиях, зависит от типа и состояния грунта. В области статистического девиаторного разрыхления исследованные грунты имеют меньшую тенденцию к разрыхлению, чем при однократном нагружении.

Прочностные характеристики, определенные статистической обработкой экспериментальных данных, показывают, что в общем случае параметры прочности исследованных грунтов в 


\begin{tabular}{|c|c|c|c|c|c|c|}
\hline Impact Factor: & $\begin{array}{l}\text { ISRA (India) } \\
\text { ISI (Dubai, UAF } \\
\text { GIF (Australia) } \\
\text { JIF }\end{array}$ & $\begin{array}{l}=1.344 \\
=0.829 \\
=0.564 \\
=1.500\end{array}$ & $\begin{array}{l}\text { SIS (USA) } \\
\text { PИHЦ (Russia) } \\
\text { ESJI (KZ) } \\
\text { SJIF (Morocco }\end{array}$ & $\begin{array}{l}=0.912 \\
=\mathbf{0 . 2 3 4} \\
=\mathbf{3 . 8 6 0} \\
=\mathbf{2 . 0 3 1}\end{array}$ & $\begin{array}{l}\text { ICV (Poland) } \\
\text { PIF (India) } \\
\text { IBI (India) }\end{array}$ & $\begin{array}{l}=6.630 \\
=1.940 \\
=4.260\end{array}$ \\
\hline
\end{tabular}

различной степени зависят от типа и состояния

грунта (таблица 1).

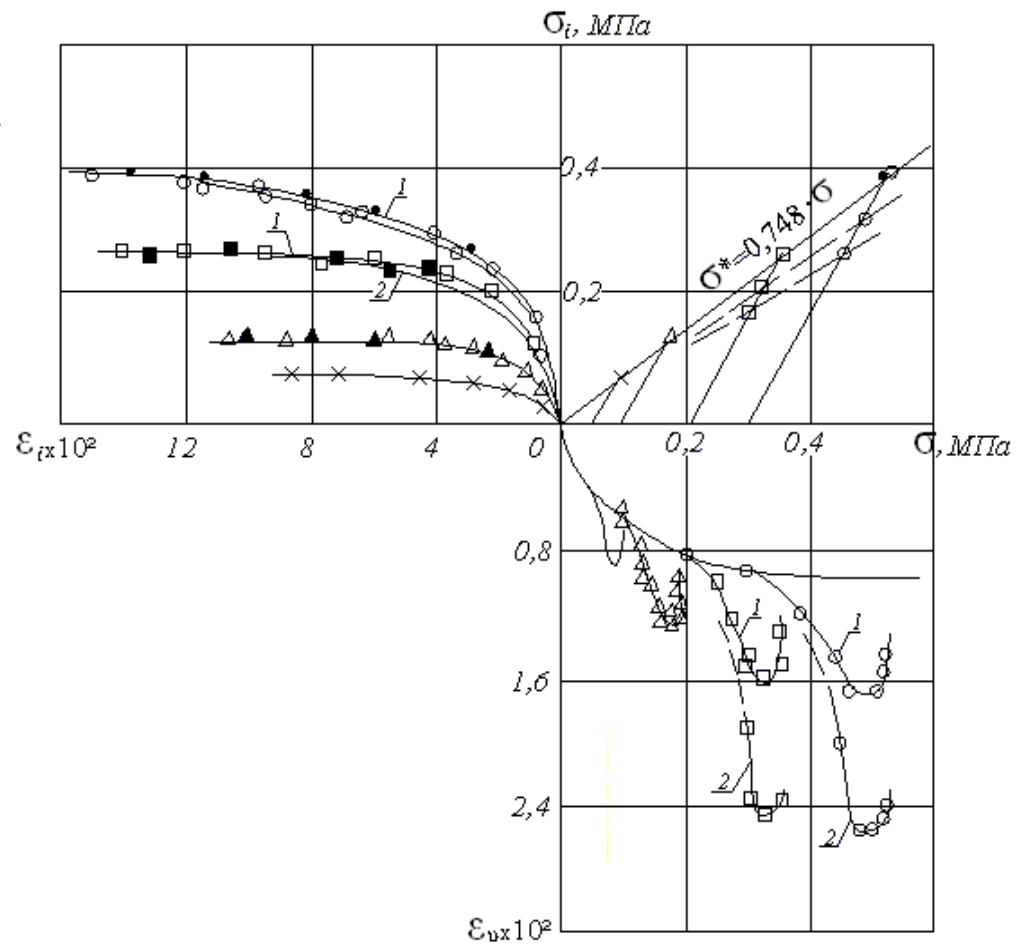

Рисунок 3 - Паспорт испытания грунта.

Песок средней крупности, в воздушно-сухом состоянии: 1-статика; 2-циклика

Таблица 1

Величин предельных интенсивностей касательных напряжений при однократном нагружении и предварительном циклическом воздействии.

\begin{tabular}{|c|c|c|c|c|c|c|}
\hline \multirow{2}{*}{$\begin{array}{c}\text { Наименование } \\
\text { грунта }\end{array}$} & \multirow{2}{*}{$\begin{array}{c}\text { Плотность } \\
\text { сухого } \\
\text { грунта } \\
\end{array}$} & \multirow[t]{2}{*}{ Влажность } & \multicolumn{3}{|c|}{ Напряжения, МПа } & \multirow{2}{*}{$\begin{array}{c}\text { Отклонения } \\
\%\end{array}$} \\
\hline & & & $\sigma_{o}$ & $\sigma_{i}^{*}$ & $\sigma_{i(N)}^{*}$ & \\
\hline \multirow[t]{2}{*}{ Песок мелкий } & \multirow[t]{2}{*}{1,56} & \multirow[t]{2}{*}{0,02} & 0,20 & $\frac{0,260}{0,258}$ & $\frac{0,256}{0,262}$ & $\begin{array}{l}+1,54 \\
-1,55\end{array}$ \\
\hline & & & 0,30 & $\frac{0,396}{0,400}$ & $\frac{0,398}{0,393}$ & $\frac{-0,50}{+1,75}$ \\
\hline \multirow[t]{4}{*}{$\begin{array}{l}\text { Песок средней } \\
\text { крупности }\end{array}$} & \multirow[t]{4}{*}{1,63} & \multirow[t]{2}{*}{0,01} & 0,20 & $\frac{0,262}{0,257}$ & $\frac{0,259}{0,261}$ & $\frac{+1,14}{-1,55}$ \\
\hline & & & 0,30 & $\frac{0,391}{0,387}$ & $\frac{0,386}{0,390}$ & $\frac{+1,28}{-0,77}$ \\
\hline & & \multirow[t]{2}{*}{0,04} & 0,20 & $\underline{0,238}$ & $\underline{0,243}$ & $\frac{-2,10}{+2,24}$ \\
\hline & & & 0,30 & $\underline{0,355}$ & $\frac{0,352}{0,353}$ & $\begin{array}{l}+1,12 \\
-0,28\end{array}$ \\
\hline
\end{tabular}

Примечание: в числителе и знаменателе приведень результаты двух повторностей.

\section{Conclusion}

Сравнение величин предельных интенсивностей касательных напряжений для соответствующих значений напряжений гидростатического обжатия, полученных при однократном нагружении и предварительном циклическом воздействии песчаных грунтов (табл.1), свидетельствуют о том, что отклонения их не превышают $\pm 3 \%$. В связи с этим отсутствие закономерности в отклонениях позволяет отнести их за счет разбросов, обусловленных точностями подготовки образцов и измерения в приборах. 


\begin{tabular}{|c|c|c|c|c|c|c|}
\hline Impact Factor: & $\begin{array}{l}\text { ISRA (India) } \\
\text { ISI (Dubai, UAE } \\
\text { GIF (Australia) } \\
\text { JIF }\end{array}$ & $\begin{array}{r}=1.344 \\
=0.829 \\
=0.564 \\
=1.500\end{array}$ & $\begin{array}{l}\text { SIS (USA) } \\
\text { PИHЦ (Russia) } \\
\text { ESJI (KZ) } \\
\text { SJIF (Morocco) }\end{array}$ & $\begin{array}{l}=0.912 \\
=0.234 \\
=3.860 \\
=\mathbf{2 . 0 3 1}\end{array}$ & $\begin{array}{l}\text { ICV (Poland) } \\
\text { PIF (India) } \\
\text { IBI (India) }\end{array}$ & $\begin{array}{l}=6.630 \\
=1.940 \\
=4.260\end{array}$ \\
\hline
\end{tabular}

Таким образом, в общем случае, предварительное циклическое воздействие оказывает существенное влияние на деформируемость грунтов, тогда как влияния их на прочность не установлено, и это согласуется с результатами $[1,2,9,10]$.

\section{References:}

1. Zareckij JK (1988) Statika i dinamika gruntovyh plotin. - M.: Strojizdat. -352p.

2. Zareckij JK (1989) Lekcii po sovremennoj mehanike gruntov.- Rostov-na-Donu: Izdatel'stvo Rostovskogo universiteta. $-608 \mathrm{~s}$.

3. Zareckij JK (1988) Vjazkoplastichnost' gruntov i raschety sooruzhenij. - M.: Strojizdat. -352p.

4. Voroncov JI, Azbergenov MI (1987) Ocenka vlijanija ciklicheskogo nagruzhenija peschanyh gruntov na ih deformaciju / Sb. nauchnyh trudov Gidroproekta, vyp. 124. - Moscow. p.141-147.

5. Azbergen MI (1997) Nelinejnaja deformiruemost' gruntov i uchet povtornosti nagruzhe $\neg$ nija. - Almaty: Gylym. $-96 \mathrm{p}$.

6. Azbergen MI (2012) Izbrannye voprosy geotehniki. - Almaty: Jevero. -116p.
7. Azbergen MI (2015) Deformacii gruntov pri trehosnom szhatii (kazahskom jazyke).

Taraz: «Format-print». $-116 \mathrm{p}$.

8. Azbergen MI (2016) Deformacii gruntov pri trehosnom ciklicheskom szhatii (kazahskom jazyke). - Taraz: «Format-print». -120p.

9. Ivanov PL, Itina LI, Pospelov VA (1977) Vlijanie dinamicheskih nagruzok na prochnost' peschanyh gruntov. V kn.: Dinamika osnovanij i sooruzhenij/ Materialy 1U Vsesojuznoj konferencii. - Tashkent: Fan, t.1, p.200-203.

10. Pospelov VA (1977) Opredelenie mehaniicheskih harakteristik peskov na stabilometre s dinamicheskimi nagruzkami. V kn.: Dinamika osnovanij, fundamentov podzemnyh sooruzhenij /Materialy 1U Vsesojuznoj konferencii. - Tashkent: Fan, t.1, p.179-182. 